\title{
Alzheimer's disease: targeting the glutamatergic system
}

\author{
Myra E. Conway
}

Received: 18 November 2019/ Accepted: 29 January 2020/Published online: 11 February 2020

(C) The Author(s) 2020

\begin{abstract}
Alzheimer's disease (AD) is a debilitating neurodegenerative disease that causes a progressive decline in memory, language and problem solving. For decades mechanism-based therapies have primarily focused on amyloid $\beta$ (A $\beta$ ) processing and pathways that govern neurofibrillary tangle generation. With the potential exception to Aducanumab, a monotherapy to target $A \beta$, clinical trials in these areas have been challenging and have failed to demonstrate efficacy. Currently, the prescribed therapies for AD are those that target the cholinesterase and glutamatergic systems that can moderately reduce cognitive decline, dependent on the individual. In the brain, over $40 \%$ of neuronal synapses are glutamatergic, where the glutamate level is tightly regulated through metabolite exchange in neuronal, astrocytic and endothelial cells. In $\mathrm{AD}$ brain, $\mathrm{A} \beta$ can interrupt effective glutamate uptake by astrocytes, which evokes a cascade of events that leads to neuronal swelling, destruction of membrane integrity and ultimately cell death. Much work has focussed on the post-synaptic response with little
\end{abstract}

M. E. Conway

Faculty of Health and Applied Sciences, University of the West of England, Coldharbour Lane, Bristol BS16 1QY, UK

M. E. Conway ( $\bowtie)$

Faculty of Health and Life Sciences, University of the West of England, Coldharbour Lane, Bristol BS16 1QY, UK

e-mail: myra.conway@uwe.ac.uk insight into how glutamate is regulated more broadly in the brain and the influence of anaplerotic pathways that finely tune these mechanisms. The role of blood branched chain amino acids (BCAA) in regulating neurotransmitter profiles under disease conditions also warrant discussion. Here, we review the importance of the branched chain aminotransferase proteins in regulating brain glutamate and the potential consequence of dysregulated metabolism in the context of BCAA or glutamate accumulation. We explore how the reported benefits of BCAA supplementation or restriction in improving cognitive function in other neurological diseases may have potential application in $\mathrm{AD}$. Given that memantine, the glutamate receptor agonist, shows clinical relevance it is now timely to research related pathways, an understanding of which could identify novel approaches to treatment of AD.

Keywords Glutamate - Aging - Alzheimer's disease $\cdot$ BCAT $\cdot$ Branched chain amino acids

$\begin{array}{ll}\text { Abbreviations } \\ \text { KIC } & \alpha \text {-Ketoisocaproate } \\ \text { KIV } & \alpha \text {-Ketoisovalerate } \\ \text { KMV } & \alpha \text {-Keto- } \beta \text {-methylvalerate } \\ \text { AD } & \text { Alzheimer's disease } \\ \text { A } \beta & \text { Amyloid } \beta \\ \text { APP } & \text { Amyloid precursor protein } \\ \text { BCAA } & \text { Branched chain amino acids } \\ \text { BCAT } & \text { Branched chain aminotransferase }\end{array}$




\begin{tabular}{|c|c|}
\hline BCATc & Cytosolic BCAT \\
\hline BCATm & Mitochondrial BCAT \\
\hline BCKA & Branched chain $\alpha$-keto acids \\
\hline BCKD & $\begin{array}{l}\text { Branched chain } \alpha \text {-keto acid } \\
\text { dehydrogenase }\end{array}$ \\
\hline Cho & Choline \\
\hline $\mathrm{Cr}$ & Creatinine \\
\hline Glu & Glutamate \\
\hline Glx & Glu+glutamine \\
\hline GDH & Glutamate dehydrogenase \\
\hline MSUD & Maple syrup urine disease \\
\hline NAA & $N$-acetyl aspartate \\
\hline NMDAR & $N$-methyl-D-aspartate receptor \\
\hline NFTs & Neurofibrillary tangles \\
\hline PLP & Pyridoxal phosphate \\
\hline PSEN1 & Presenilin 1 \\
\hline${ }^{1} \mathrm{H}$ MRS & Proton magnetic resonance spectroscopy \\
\hline $\mathrm{mI}$ & Myoinositol \\
\hline TBI & Traumatic brain injury \\
\hline
\end{tabular}

\section{Introduction}

Dementia is defined as a loss in memory or brain function that affects an individuals day-to-day living, where they present with a range of symptoms including memory loss, difficulty with problem solving or language. According to the World Health Organisation, there is an estimated 46.8 million people worldwide living with dementia that is predicted to almost double every 20 years. The types of dementia vary with respect to the areas of the brain affected, related symptom patterns and the underlying pathology that include (but are not limited to) Alzheimer's disease (AD), Vascular dementia, mixed dementia, dementia with Lewy bodies and Frontotemporal dementia (reviewed in Alzheimer's Association 2016). AD, which reflects about $64 \%$ of cases, is a progressive neurodegenerative disorder characterised by the accumulation of extracellular amyloid $\beta$ peptide (A $\beta$ ) and intracellular neurofibrillary tangles (NFTs) associated with extensive neuronal cell death and loss of brain volume. $N$-methyl-D-aspartate receptor (NMDAR) activation and related excitotoxic events that lead to synaptic dysfunction has also been associated with AD pathology (Liu et al. 2019). The aetiology of $\mathrm{AD}$ is not well understood, but is often characterised as early-onset familial $\mathrm{AD}$ (less than 65 years of age) and late onset $\mathrm{AD}$ (greater than 65 years of age) (Tellechea et al. 2018; Wattmo and Wallin 2017). Diagnosis is therefore confounded by the complexity of disease pathology and classification, where the incidence and prevalence increases significantly with age. Confirmation of AD can only be given at autopsy when morphological and histological examinations have been validated.

Whilst defective amyloid precursor protein (APP) processing and $A \beta$ aggregation more than likely contribute to $\mathrm{AD}$ pathology the number of plaques generated do not always reflect disease severity, indicating that other factors, such as genetics and environmental cues, have a role in disease progression. Neuronal loss has also been related to the dysregulation of the cholinergic system and glutamatergic system (Ferreira-Vieira et al. 2016). Deficits in these systems can influence memory, cognition and behaviour, including cortical and hippocampal processing. Currently, prescribed treatments for AD are based on cholinesterase inhibitors (galantamine, rivastigmine and donepezil) or glutamatergic targets (memantine) (Table 1). Whilst these treatments offer some reprive to symptoms, the improvement is modest and temporary, indicating that like $\mathrm{A} \beta$ targeted approaches, the heterogenity of the disease calls for a stratified approach for effective treatment. Based on genome-wide association studies, over 20 genetic risk factors have been suggested to feature strongly in AD pathology e.g. those carrying the APOE4 allele are considered to be at higher risk of developing AD. Factors that regulate metabolism in particular glucose and cholesterol metabolism together with autophagyrelated recycling pathways and inflammatory responses involving microglial activation show wide genetic and epidemiological correlations. Hypertension, vascular risk factors and diabetes are also considered to adversely influence risk (reviewed in Lane et al. 2018).

In this review, we discuss how brain glutamate (Glu) levels change as we age, how metabolism and nutrition regulate this neurotransmitter and how excitotoxicity causes neurodegeneration. We highlight the importance of Glu regulation in pre-synaptic neurons and how anaplerotic pathways governed by aminotranferase proteins, such as the branched chain aminotransferase (BCAT), play an integral role in regulating brain Glu. We offer insight into how these 
Table 1 Current FDA approved drugs to treat AD

\begin{tabular}{llll}
\hline Drug & Trade name & Mode of action & Treatment stage \\
\hline Donepezil & Aricept & Acetylcholinesterase inhibitor & All stages \\
Galantamine & Razadyne & Acetylcholinesterase inhibitor ${ }^{\mathrm{a}}$ & Mild to moderate \\
Rivastigmine & Exelon & Acetylcholinesterase inhibitor & Mild to moderate \\
Memantine & Namenda & NMDA receptor antagonist & Mild \\
Donepezil + memantine & Namzaric & Acetylcholinesterase inhibitor + NMDA receptor antagonist & Moderate to severe $^{\text {b }}$ \\
\hline
\end{tabular}

${ }^{\mathrm{a}}$ May delay or slow worsening of symptoms. Effectiveness varies from person to person

${ }^{\mathrm{b}}$ Effective in individuals with moderate to severe $\mathrm{AD}$ who are taking a cholinesterase inhibitor might benefit by also taking memantine

proteins and the branched chain amino acids (BCAAs) may present novel targets to delay the progression of AD.

The amyloid and Tau hypothesis

The search for mechanism-based therapies has focussed on the histopathological and morphological changes and their related effect on cognitive decline. Early-onset familial AD caused by mutations in the APP gene or in genes of proteins important to APP processing, including presenilin 1 (PSEN1) and presenilin 2, support the hypothesis that defective APP processing is a key factor in AD pathology (Reitz et al. 2011; Nizzari et al. 2012). Processing of the APP by $\alpha$, $\beta$, and $\gamma$ secretases can be summarised in the nonamyloidogenic and amyloidogenic pathway (Fig. 1) (reviewed in O'Brien and Wong 2011; Tiwari et al. 2019). In brief, the non-amyloidogenic pathway generates soluble APP $\alpha$, the non-toxic peptide P3 and the APP intracellular domain. In neurons, A Disintegrin and metalloproteinase domain-containing protein 10 (ADAM10) and ADAM17 are considered the major $\alpha$-secretases that cleave within the $A \beta$ domain. In the amyloidogenic pathway, $\beta$-site APP cleavage enzyme 1 (BACE-1) cleavage occurs at the $\mathrm{N}$-terminus of the A $\beta$ peptide generating APP- $\beta$ and $\beta$ C-terminal fragment ( $\beta$-CTF). This is followed by $\gamma$ secretase cleavage generating the A $\beta$ peptide. The $\gamma$ secretase protease is composed or four individual proteins: PSEN1, nicastrin, anterior pharynx defective 1 (Aph1), and presenilin enhancer 2 . The resulting $A \beta$ [A $\beta(1-40)$ and $A \beta(1-42)]$ peptides can aggregate to form oligomers that are found in senile plaques evident in $\mathrm{AD}$ brain. Associated neurotoxic events

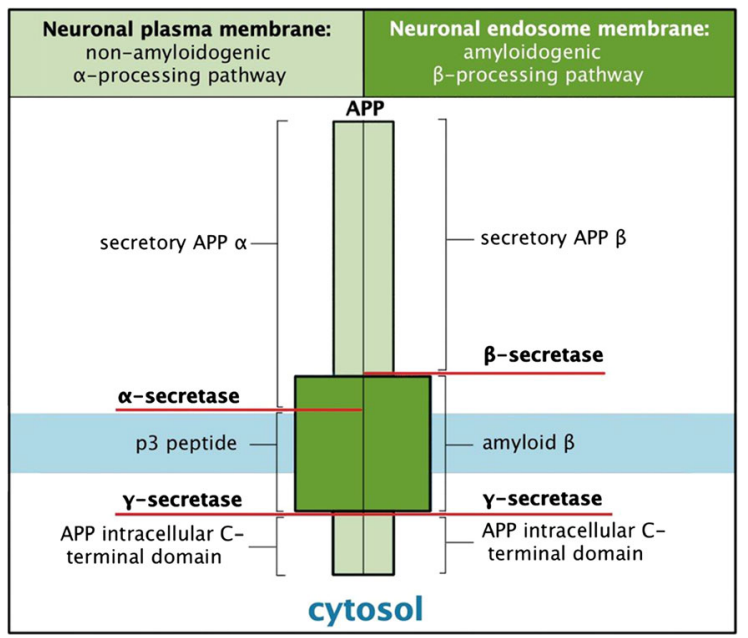

Fig. 1 Amyloid precursor protein processing pathways.APP undergoes either $\alpha$ or $\beta$ secretase processing generating the secretory $\mathrm{APP} \alpha$ subunit or the secretory APP $\beta$ subunit, respectively. Subsequent cleavage by $\gamma$-secretase generates the p3 peptide and $\mathrm{A} \beta$ for the amyloidogenic and non-amyloidogenic pathway, respectively. (Moraes and Gaudet 2018) with permission from Oxford University Press

include generation of ROS, loss of mitochondrial function (Reddy and Beal 2008), disruption of calcium homestasis together with neuroinflammation due to microglia activation by A $\beta$ (Cai et al. 2014). Decades of clinical trials dedicated to target $\mathrm{A} \beta$ processing have failed to generate a treatment for $\mathrm{AD}$ (Tolar et al. 2019). The most recent trial with Aducanumab (BIIB037), a monoclonal antibody that targets $A \beta$, failed to reach primary endpoint targets in March, 2019, where an indepdendent data monitoring committee determined that there was insufficient evidence to support drug efficacy. However, in this study, two Phase III trials, ENGAGE and EMERGE were running 
consecutively, where EMERGE was later shown to be 'trending postive'. Subsequent analysis of this larger data set with a focus on the outcome of people on the highest aducanumab dose showed a significant reduction in decline on the primary endpoint but also on secodnary endpoints such as MMSE and ADAS-Cog. These discrepancies were reportedly due to a change in the trial protocols. Based on these outcomes, Biogen plan to apply for regulatory approval in the US in 2020. Should this succeed this will be the first therapeutic agent to target $\mathrm{A} \beta$ and show promise in the treament of $\mathrm{AD}$.

The second major molecular pathway identified as a therapeutic target is based on the tau protein, which has a microtubule binding domain and plays a critical role in tubulin assembly and stabilisation of microtubules (Duan et al. 2017). In AD, hyperphosphorylation of tau results in a conformational change that causes microtubule destabilisation and aggregate accumulation forming NFTs. When microtubule dynamics are dysregulated, neuronal integrity is compromised and degeneration follows. This is further precipitated by the aggregation of tau generating NFTs, which is thought to block axonal and dendritic transport in neurons. Accumulation of $A \beta$ and NFTs has associated negative effects on neurotransmitter systems such as the Cholinergic and Glutamatergic system that impair long-term potentiation and synaptic plasticity (Ferreira-Viera et al. 2016; Benussi et al. 2019; Hynd et al. 2004).

\section{Brain glutamate}

Glutamate in the brain, aging and AD-related changes

Glutamate is one of the major excitatory neurotransmitters in the mammalian brain, important in memory, learning, cognition, motor behaviour as well as the immediate precursor to GABA and glutathione (Danbolt 2001). Under normal physiological conditions Glu plays a role in dendrite and synapse formation. Glutamatergic activity can be measured using proton magnetic resonance spectroscopy ( ${ }^{1} \mathrm{H}$ MRS) (Hall et al. 2012; Bookheimer et al. 2000), that is reflective of neuronal integrity. The use of ${ }^{1} \mathrm{H}$ MRS has also emerged as a promising tool in neurological and psychiatric disorders including the investigation of
AD (Wang et al. 2015a, b; Su et al. 2016) and ALS (Kalra 2019). Age-related changes in selected ${ }^{1} \mathrm{H}$ MRS biomarkers have been reported, where lower concentrations of Glu recorded in the motor cortex positively correlated with $\mathrm{N}$-acetyl aspartate (NAA) and creatinine $(\mathrm{Cr})$ consistent with neuronal loss/ shrinkage with age (Kaiser et al. 2005). Until recently, measurement of GABA using ${ }^{1} \mathrm{H}$ MRS was less reliable, but it has been shown that like Glu it declines with age in the human brain (Gao et al. 2013).

Furthermore, ${ }^{1} \mathrm{H}$ MRS was found to improve prognostic accuracy for conversion from mild cognitive impairment (MCI) to dementia (Modrego et al. 2005) and even from cognitive health to MCI (Kantarci et al. 2017). A meta-analysis by Wang et al. reported a significant reduction in NAA in the posterior cingulate $(\mathrm{p}<0.005)$ and bilateral hippocampus $(\mathrm{p}<0.005)$ in $\mathrm{AD}$ patients (Wang et al. $2015 \mathrm{a}, \mathrm{b})$. A decrease in the NAA/Cr ratio together with an increase in the $\mathrm{mI} / \mathrm{Cr}$ ratio was also observed, indicating that collectively these markers hold promise as biomarkers of brain function and more importantly evidence that the glutamatergic pathway is important in $\mathrm{AD}$ pathology. Concentrations of Glu were also shown to be lower in the posterior cingulate cortex of AD patients, either when measured alone or as a combined measure of Glu+glutamine (Glx) (Antuono et al. 2001; Fayed et al. 2011; Rupsingh et al. 2011). Related studies showed that a combination of Choline/Cr, Glx/Cr, and NAA/Cr ratios in the posterior cingulate cortex successfully differentiated between carriers from non-carriers of a fully penetrant, early onset familial (PSEN1 gene) mutation at different disease stages (Londono et al. 2014). However, few studies report the measurement of $A \beta$ aggregates (measured by positron emission tomography) and their association with ${ }^{1} \mathrm{H}$ MRS (Kantarci 2007). In a pilot study, GABA, Glx and NAA were assessed in the posterior cingulate cortex relative to cognitive assessments, A $\beta$ deposition, and APOE genotype of healthy control compared with amnestic MCI (aMCI) subjects (Riese et al. 2015). Here, levels of these biomarkers were significantly reduced in aMCI and correlated with CERAD (The Consortium to Establish a Registry for Alzheimer's Disease) word learning performance. Although, a correlation between GABA and Glx was not associated with $\mathrm{A} \beta$ deposition or APOE genotype, further longitudinal studies are warranted as the prognostic value of these biomarkers relative to $A \beta$ 
or conversion to $\mathrm{AD}$ may hold promise. The authors also reflected that this does not rule out potential correlations between these biomarkers and $\mathrm{A} \beta$ load in other brain areas such as the hippocampus. Together, ${ }^{1} \mathrm{H}$ MRS studies confirm that glutamatergic neurotransmission decreases as we age but is further perturbed in individuals with aMCI and AD, respectively and correlates with cognitive measures.

\section{Glutamate/glutamine cycle}

Glutamate is extensively distributed throughout the CNS (Collingridge and Lester 1989). Regulation of brain Glu is thought to be primarily governed through the Glu/glutamine cycle, where excess Glu remaining after excitation is taken up by astrocytes (Fig. 2) (reviewed in Conway and Hutson 2016; Yudkoff 2017). At rest, the concentration of Glu in the synaptic cleft is around 0.6 $\mu \mathrm{M}$ (Bouvier et al. 1992) but debate exists as to the actual concentration (reviewed in Fetherstone and Shippy 2008). Following presynaptic neuronal depolarisation, synaptic vesicles that store glutamate, first fuse with the membrane and then release Glu into the synapse. Glutamate can then activate a variety of ionotropic and metabotropic

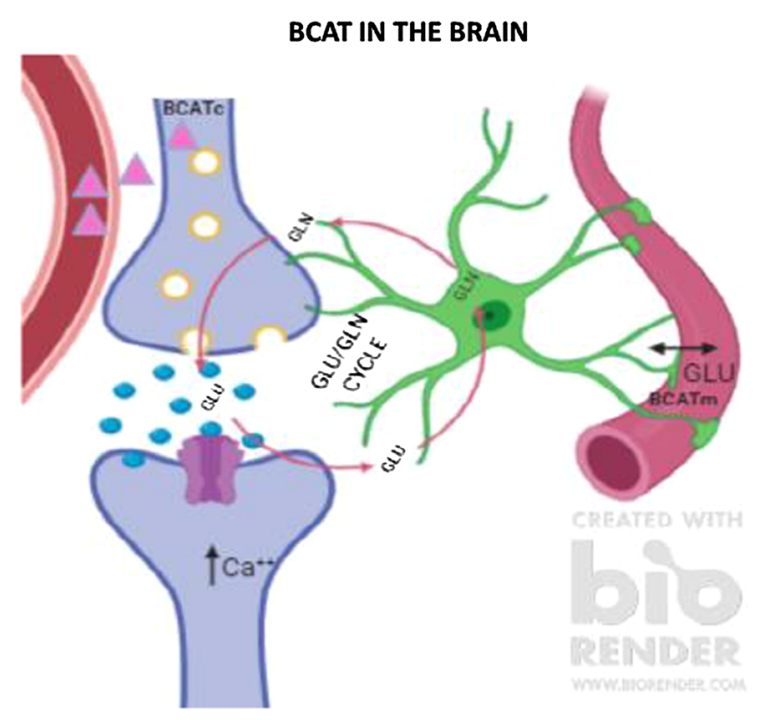

Fig. 2 BCAT metabolism in the human brain. Leucine $(\Delta)$ readily crosses the blood brain barrier and undergoes BCATc transamination in neuronal cells producing glutamate. Excess glutamate generated during excitation is taken up by astrocytes, where glutamate is regenerated through the glutamate/glutamine cycle. Glutamate may also be removed by endothelial cells of the vasculature. (Image generated using BioRender) receptors on postsynaptic and presynaptic neurons as well as glial cells. During excitation the level of Glu increases to $10 \mu \mathrm{M}$ (Clements et al. 1992), where overstimulation is prevented by the rapid and efficient removal from the extracellular space. This is facilitated by astrocytes that express high levels of the Glu specific transporter (GLAST/EAAT1 and GLT1/ EAAT2). Glutamate is converted through amidation to glutamine by the microsomal enzyme glutamine synthetase (restricted to astrocytes). As glutamine is non-neuroactive it can be released into the ECF for reuptake by the pre-synaptic neuron. This then replenishes the store of Glu through deamidation by mitochondrial phosphate-dependent glutaminase and packaged into synaptic vesicles for reuse. Whilst the glutamate/glutamine cycle is an efficient method to regenerate Glu, this recycling is not $100 \%$ effective. During its transition some Glu is 'lost' in astrocytes through metabolism, generating lactate (Sonnelwald et al. 1993), or in the production of purines and glutathione (Shank et al. 1985). As a result, anaplerotic pathways must interface with the Glu-glutamine cycle to regenerate this 'lost' Glu necessary to sustain efficient neurotransmission. This is in part facilitated by pyruvate carboxylase (Gamberino et al. 1997), an enzyme found solely in astrocytes that utilizes brain $\mathrm{CO}_{2}$ to replenish the carbon required for the TCA cycle, which as a result contributes to the overall concentration of glutamine produced (Oz et al. 2004). A limiting factor in this reaction is the source of nitrogen, where the BCAAs, aspartate and more recently alanine serve as potential nitrogen donors (Hutson et al. 1998, 2001; Lieth et al. 2001; Bixel et al. 1997, 2001; Yudkoff et al. 1983, 1996; Kanamori et al. 1998). The regulation of brain Glu is important as uptake from the blood is minimal, however, precursors to its synthesis such as the BCAAs are easily taken up, in particular leucine (Oldendorf et al. 1977; Smith et al. 1987). The BCAAs are metabolised through a series of reactions involving BCAT and the rate limiting oxidation step catalysed by the branched chain $\alpha$-keto acid dehydrogenase (BCKD) complex.

The branched chain aminotransferase proteins

The canonical role of the BCAT proteins is the transamination of the BCAAs, leucine, isoleucine and valine with $\alpha$-keto glutarate to form Glu and their respective branched chain $\alpha$-keto acids (BCKA) $(\alpha-$ 
ketoisocaproate (KIC), $\alpha$-keto- $\beta$-methylvalerate (KMV) and $\alpha$-ketoisovalerate (KIV)) regenerating the pyridoxal phosphate (PLP) form of the enzyme (Ichihara and Koyama 1966) (Fig. 3). Complete oxidation of the BCAAs is facilitated through the BCKD complex (Harris et al. 2004). Glutamate dehydrogenase (GDH), a mitochondrial matrix enzyme, is responsible for the oxidative deamination of Glu to $\alpha-\mathrm{KG}$ and free $\mathrm{NH}_{4}{ }^{+}$, using either $\mathrm{NAD}^{+}$or $\mathrm{NADP}^{+}$as a co-factor. The BCATm:BCKD complex and BCATm:GDH form metabolons, which facilitate effective substrate channelling (Islam et al. 2007, 2010; Hutson et al. 2011). Whole body tissue expression and compartmentation of these proteins drives intra- and inter-organ exchange of nitrogen and carbon (Hutson and Harper 1981). Unlike all other amino acids, the BCAAs do not undergo transamination in the liver but are directed to skeletal muscle, one of the main sites of BCAA uptake. Because skeletal muscle transaminase activity exceeds the oxidative capacity, BCAAs act as nitrogen donors in peripheral metabolism (Hutson et al. 1978). In the central nervous system transamination and oxidation also exhibit cell-specific localization and participate in nitrogen and carbon shuttles (Hutson et al. 1998). For the purpose of this review we will focus on the role of the BCAT protein in the brain, in particular with respect to the regulation of brain Glu.

Cellular distribution of branched chain aminotransferases

The basis for regulating brain Glu originates in part due to the distinct subcellular location and tissue specificity of the BCAT proteins (Daikin and Yudkoff 2000). These enzymes are indispensable and have been reported in most tissues with varied expression levels. Of those studied to date there are two main

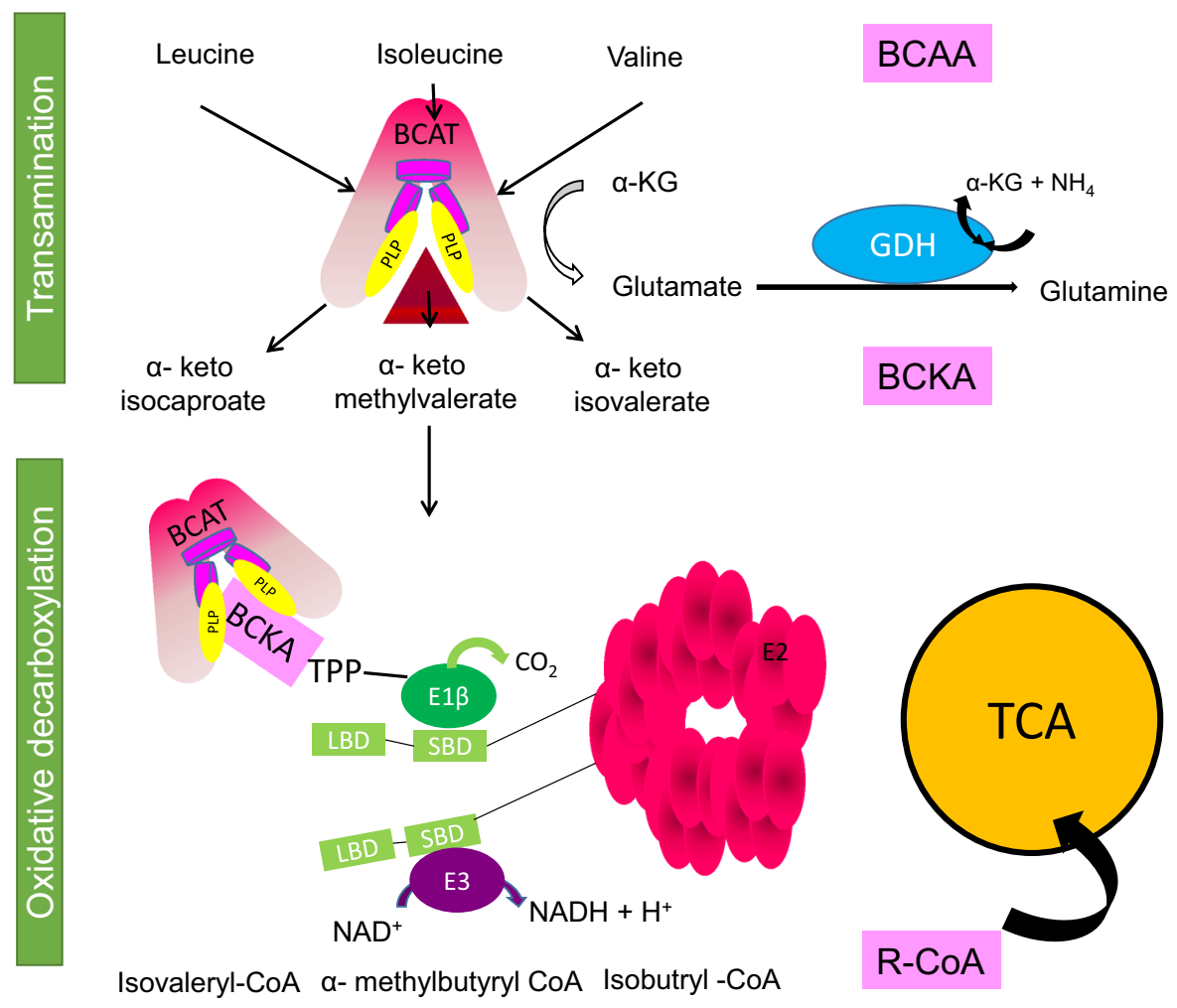

Fig. 3 Branched chain amino acid (BCAA) oxidation. Transamination of the BCAAs, leucine, isoleucine and valine with $\alpha$-keto glutarate forming the respective $\alpha$-keto acids, (BCKAs: $\alpha$-ketoisocaproate (KIC), $\alpha$-keto- $\beta$-methylvalerate (KMV) and $\alpha$-ketoisovalerate (KIV)) and glutamate, regenerating the enzyme. Subsequent oxidation by the branched chain $\alpha$-keto acid dehydrogenase complex generates the branched chain acyl CoA, which enter the TCA cycle. Glutamate can be further metabolised by glutamate dehydrogenase to generate glutamine. (Adapted from Conway and Hutson 2016) 
isoforms, cytosolic, BCATc and mitochondrial, BCATm, encoded by two different genes. The cytosolic form has been identified primarily from brain, placenta and ovary (Hall et al. 1993; Hutson 1988; Hutson et al. 1998; Sweatt et al. 2004a, b; Garcia-Espinosa et al. 2007). The mitochondrial isoform, is responsible for the majority of transamination outside the central nervous system. The highest levels of BCATm recorded are in the pancreas, kidney, stomach and brain (Suryawan et al. 1998). Only variants of BCATm have been described, a novel alternatively spliced PP18b variant found in placental tissue (Lin et al. 2001) and a novel co-repressor for thyroid hormone nuclear receptors (P3) (Than et al. 2001). Although the biological significance of these variants remains to be determined, P3 has been shown to act as a corepressor for thyroid hormone nuclear receptors. More recently, a clinically relevant mutant form of BCATm has been reported, which has homozygous or compound heterozygous BCAT2 mutations, discussed in Mutations of BCAT leads to mild cognitive impairment and brain lesions Section (Wang et al. 2015a, b; Knerr et al. 2019).

The distribution of BCAT in the brain was first characterised in rat and murine models (Oldendorf 1977; Bixel et al. 1997; Bixel et al. 2001; Sweatt et al. 2004a, b; Garcia-Espinosa et al. 2007). Our group subsequently mapped BCATc to the human brain, where it was found in all brain regions and consistent with the rat model was neuron-specific, with strongest labelling reported in the parietal cortex (Hull et al. 2012). The hippocampus showed intense immunoreactivity for BCATc of pyramidal cells (approximately $70 \%$ of neuronal cells) in the pyramidal cell layer, with moderate BCATc staining in the cell bodies of interneurons (GABAergic or glycine). Pyramidal cells are the primary cells lost from the neocortex in $\mathrm{AD}$ (Bussiere et al. 2003). The cell bodies of glutamatergic cells within the temporal and hippocampus showed intense staining relative to the dendrite regions, reflecting the possibility that their primary role would be to contribute to the Glu metabolic pool used to generate Glu rather than the Glu pool used during excitation. Conversely, in the areas of the supraoptic tract intense staining along axons was noted indicating an additional role of BCATc transamination in Glu release in this region. In the cerebellar cortex and granular cell layer, GABAergic neurones including stellate, basket and Golgi neurons within the molecular layer were positive for BCATc. The distribution and the varied intensities of BCATc expression in the hippocampus, where staining of the CA3 region was more intense than the CA1 region, mirrored the findings of Castellano et al. (2007), who investigated mRNA expression of BCATc in postnatal and adult brains of mice. This pattern of BCATc staining was reported throughout the human brain evidencing that BCATc is important in glutamatergic and GABAergic neurotransmission.

What was clear was that wherever BCATc staining occurred BCATm was absent and vice versa (Fig. 4). Immunopositive staining for BCATm was vessel and capillary in nature. This staining was evident in all major anatomical regions of the brain assessed with the exception of the parietal lobe and medulla. Examples of areas positive for BCATm staining include the cerebral cortex, subdivisions of the basal ganglia and the diencephalon, deep nuclei and the hippocampal formation. The endothelium of capillaries and larger blood vessels were immunopositive for BCATm and showed clear, punctate staining indicative of mitochondria. The role of endothelial cells in regulating blood Glu has been researched in-depth, with a focus on transporters, which regulate Glu exchange at the blood brain barrier (O'Kane et al. 2004). Glu entry from the peripheral system to the brain is minimal, which prevents neurotoxicity, whereas brain Glu efflux is facilitated by the EAAT transporter (Chaudhry et al. 1995; O'Kane et al. 1999; Hosoya et al. 1999; Gottlieb et al. 2003; Uchida et al. 2011), the rate of which is considered to be influenced by blood Glu (Gottlieb et al. 2003; Zlotnik et al. 2008, 2012; Teichberg et al. 2009). Until the study by Helms et al. (2012), the potential for Glu metabolism within endothelial cells was not considered. Our group have shown that GDH and the BCKD complex are also expressed in endothelial cells, indicating that Glu oxidation can occur and will dependent on concentration and cellular redox state (Hull et al. 2018). The role of BCATm in endothelial cells has yet to be confirmed but most likely will be important in regulating brain glutamate through metabolism through the BCATm/ $\mathrm{BCKD} / \mathrm{GDH}$ metabolon or additional cellular roles yet to be defined. 


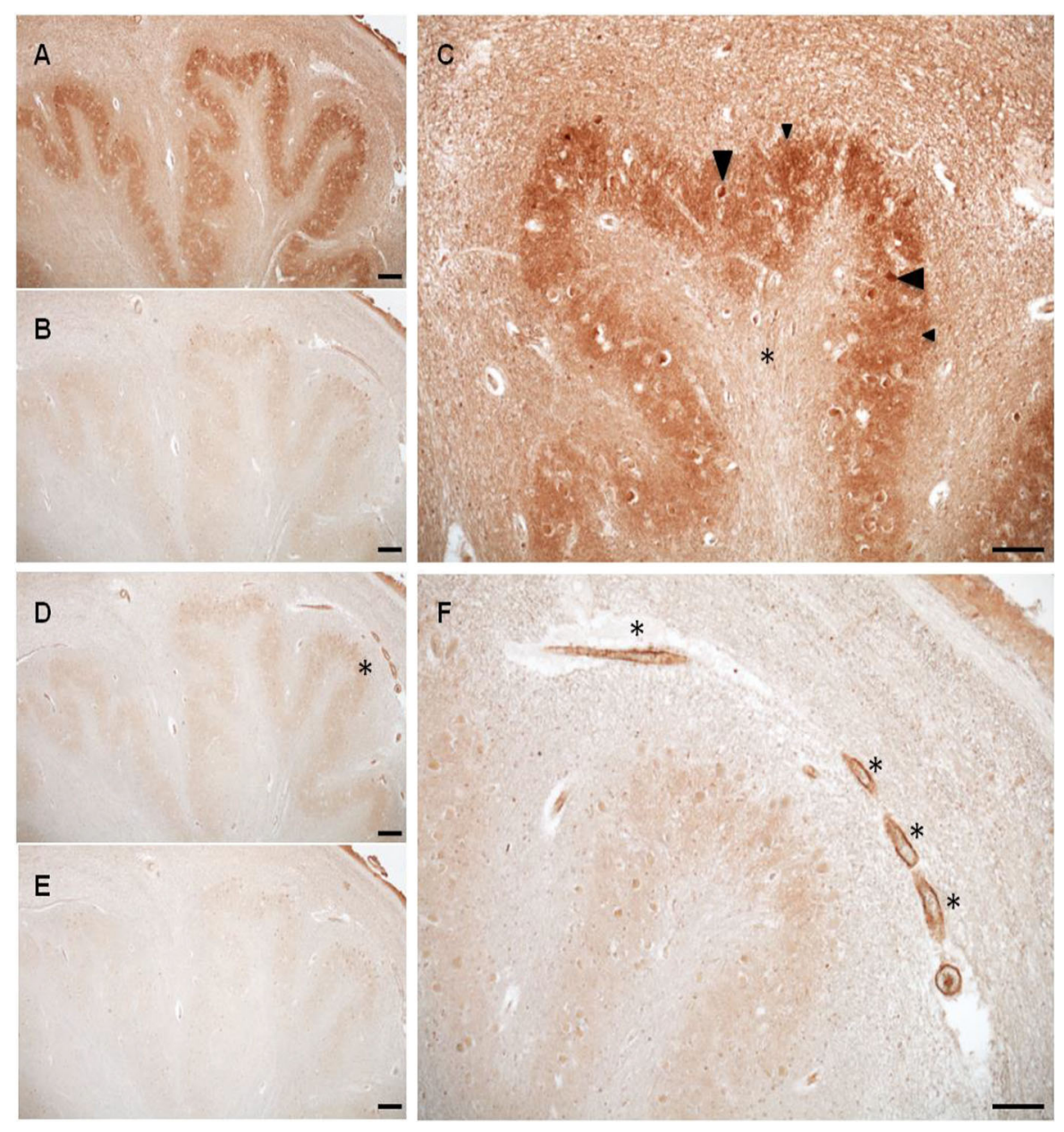

Fig. 4 Medulla BCATc and BCATm staining. a BCATc staining of the inferior olivary nucleus. $\mathbf{b}$ Antigen incubation of serial section, at $200 \times$ molar excess. $\mathbf{c}$ Increased magnification of the inferior olivary nucleus showing staining of small neurons (large arrow) and neuropil staining (small arrow) along with

The role of BCAT in brain metabolism.

Dietary BCAAs play a significant role as nitrogen donors in brain metabolism. Tracing studies of $\left[{ }^{15} \mathrm{~N}\right]$ leucine in rodent models showed that BCAAs were metabolised faster than they were incorporated into proteins in brain slices (Chaplin et al. 1976). Approximately $30 \%$ of the nitrogen of Glu/glutamine was derived from leucine alone (Brand 1981; Brand and Hauschildt 1984), which was later supported using in vivo rat brain and ex vivo rat retina models (accepted models of Glutamatergic neurons) (Lieth et al. 2001; LaNoue et al. 2001). Based on the de novo synthesis of Glu from leucine, together with the immunonegative hylum (*). d BCATm staining of the inferior olivary nucleus. e Antigen incubation of serial section, at $200 \times$ molar excess. $f$ Vessel staining (*) within the amiculum of the inferior olivary nucleus. Scale bar: a, b, d and e $200 \mu \mathrm{m}$; c and f $100 \mu \mathrm{m}$. (Hull 2012)

location of BCATm in astrocytes and BCATc in neuronal cells, it was proposed that an exchange of metabolites between these cells, governed by BCAT transamination, supports Glu synthesis and regulation of the Glu/glutamine cycle (Yudkoff et al. 1997; Hutson et al. 1998; Hutson et al. 2001). In this rat model, termed the "BCAA/BCKA shuttle", it was proposed that the distribution of BCATm to astrocytes and BCATc to neuronal cells indicated a role for transamination of BCAAs in astrocytes, generating BCKAs, which are thought to be taken up by neuronal cells to regenerate the 'lost Glu' (Hutson et al. 2001; Yudkoff 2017). However, as discussed, in human brain BCATm was found in endothelial cells 
indicating that an alternative model needs to be considered for human brain glutamate regulation.

In human brain, we propose that in neuronal cells BCAAs are transaminated by BCATc generating Glu, which contributes both to the pool of neurotransmitters and the Glu required for release during excitation. As described, Glu can be taken up by endothelial cells, which can be further metabolised or released into the blood, dependent on the serum Glu concentration. Metabolism of Glu would release $\alpha$-keto glutarate that could enter the TCA cycle. The respective BCAA, could be further oxidised for energy or be taken up by neuronal cells to regenerate the 'lost' Glu. We propose that the expression of BCATm, the BCKD complex and GDH offer an auxiliary mechanism to regulate brain Glu, in particular under conditions where the level of Glu is high, offering a neuroprotective role in the first instance (Hull et al. 2015a, b). However, in disease conditions such as $\mathrm{AD}$, Glu toxicity resulting in neuronal cell death indicates that there is a failure in this mechanism to effectively remove toxic levels of Glu. Here, a role for BCAT regulation through dietary serum BCAAs may be important.

\section{Glutamate, BCAA toxicity and neurodegeneration}

\section{Glutamate excitotoxicity}

Damage to glutamatergic neurons, in particular cell bodies and neurites in layers III and IV of the neocortex, together with damage to glutamatergically-innervated cortical and hippocampal neurons, are particularly evident in AD brain (Albin and Greenamyre 1992). Altered expression of glutamatergic transport and receptors were also reported in sporadic AD (Jacob et al. 2007), where a role for astrocyte transporters were shown to be involved with A $\beta$-induced synaptic dysfunction (Huang et al. 2018). Whilst an important neurotransmitter, pathological accumulation of Glu results in this amino acid becoming a potent neurotoxin (Choi et al. 1987; Mattson and Chan 2003). This is in part due to the time-related exposure, overstimulating the post synaptic response causing an increase in the entry of calcium into neurons (Sattler and Tymianski 2000; Mattson and Chan 2003). Several events have been linked with excitotoxicity through the NMDAR. First, the swelling of cell bodies and dendrites causes depolarisation, which depends on the extracellular concentrations of $\mathrm{Na}^{+}$and $\mathrm{Cl}^{+}$(Rothman 1985). The second event is marked by slow neuronal degeneration mediated by $\mathrm{Ca}^{++}$influx (Koh and Choi 1991). In vitro studies in which hippocampal neurons are exposed to toxic levels of $\mathrm{Glu}, \mathrm{Ca}^{++}$levels remained elevated for about $1 \mathrm{~h}$ before returning to pre-stimulus levels (Dubinsky 1993), however, over $24 \mathrm{~h} 84 \%$ of neurons expired. As calcium signalling regulates a host of cellular events the consequence of $\mathrm{Ca}^{++}$overload involves activation of catabolic enzymes including calpain I (Siman and Noszek 1988), phospholipases (Lazarewicz et al. 1990) and arachidonic metabolism (Chan and Fishman 1978). This results in an increase in reactive oxygen and reactive nitrogen species and neuronal cellular collapse through cytoskeletal breakdown and membrane degeneration. Elevated $\mathrm{Ca}^{++}$may also activate protein kinases that contribute to hyperphosphorylation of tau and ubiquitin (Mattson 1992). More recently, glutamate toxicity has been asscoiated with tau-mediated neuronal cell death and behavioural deficits in drosophila (Killian et al. 2017). NMDAR antagonists such as memantine block this receptor and can reduce the influx of $\mathrm{Ca}^{2++}$. Treatment using memantine has improved cognition, behaviour, global function but the degree of efficacy remains to be fully determined (Kishi et al. 2017; Matsunga et al. 2015). Although it is evident that the release of large concentrations of Glu into the ECF can occur under pathogenic conditions, the source of this Glu has been met with extensive debate. However, given that the highest concentration of Glu is stored in neuronal rather than glial cells, glutamatergic neurons in particular are considered the most likely source.

\section{Regional increase of BCAT in AD brain-Glu toxicity.}

Given the high expression of BCATc in glutamatergic and GABAergic neurons and its role in regulating brain Glu, our group examined the levels of the BCAT isoforms in $\mathrm{AD}$ brain. Our focus was on the main regions of the brain affected by $\mathrm{AD}$ pathology where we found a regional increase in BCATc in the hippocampus (Hull et al. 2015a, b), specifically the CA1 and CA4 region, the area first targeted by $\mathrm{AD}$ pathology (Fig. 5). An increase in the level of BCATc could be considered a compensatory response to expand the Glu pool in response to the reduced uptake 

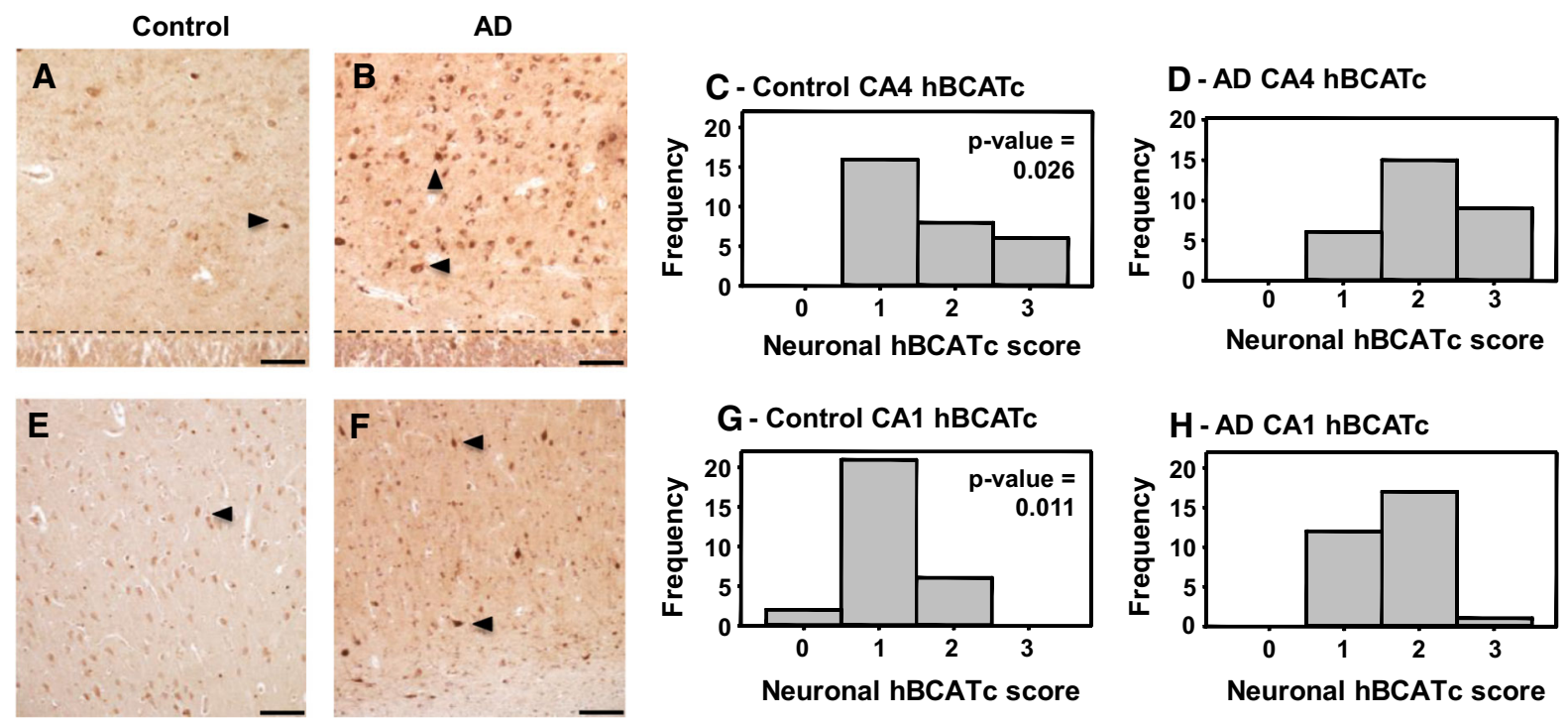

I Hippocampus
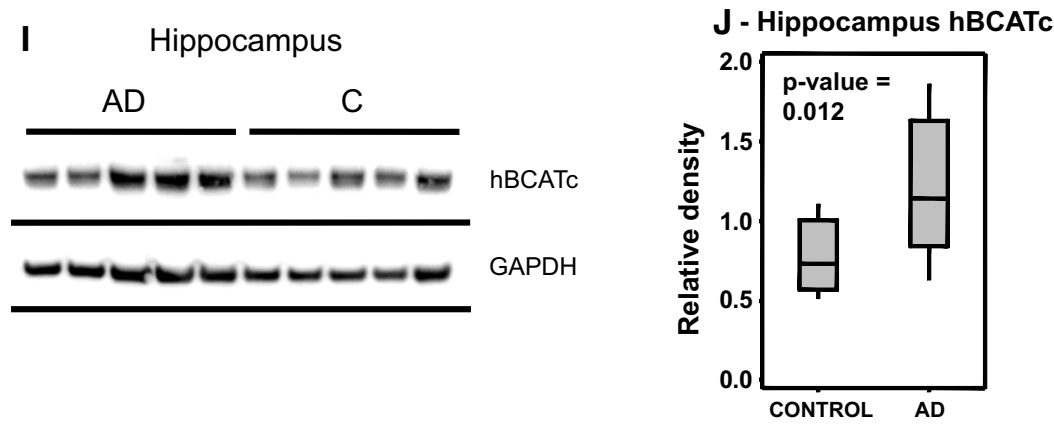

Fig. 5 Increased hBCATc expression in the hippocampus of AD brains. CA4 region of the hippocampus in a control (a) and $\mathrm{AD}$ brain (b) showing intensely labelled neurons (large arrows) and the granule cell layer (dotted line). CA1 region of the hippocampus in a control (e) and AD (f) subject showing intensely labelled neurons (large arrows). $\mathbf{c}, \mathbf{d}, \mathbf{g}, \mathbf{h}$ The slides were scored on a $0-3$ scoring system and analyzed forsignificance using the Wilcoxon-Mann-Whitney test in Minitab ${ }^{\mathrm{TM}}$ as described in materials and methods. $\mathbf{i}$ Western blot analysis of hippocampal tissue. The density of each band was measured using ImageJTM software (Wayne Rasband, National Institute of Health, USA) and analyzed for significance using a one-way ANOVA test in Minitab ${ }^{\mathrm{TM}}$. $\mathbf{j}$ Interquartile range (box) sample variability (whiskers) and the median (horizontal line within the interquartile range) are shown. Magnification for $\mathbf{a}, \mathbf{b}, \mathbf{e}$, and $\mathbf{f}$, $\times 10$. Scale bar: $200 \mu \mathrm{m}$. (Reprinted from Hull et al. (2015a) with permission from IOS Press) of synaptic Glu by astrocytes. We assigned a neuroprotective role to BCATc but proposed that should transamination in the direction of Glu synthesis persist it could exacerbate toxicity contributing to neuronal degeneration (Fig. 6). A neuroprotective role for BCATc has been reported in related animal models of brain injury. A study by Kholodilov et al. (2000) reported that following developmental striatal target injury, BCATc was upregulated in the substantia nigra of rat. However, this upregulation was evident in morphologically intact cells with no evidence of apoptotic features, supporting a role in cell survival. Upregulation of BCATc in rodent models in response to brain-derived neurotrophic factor (BDNF), subsequent to visual cortex ablation, was also associated with neuroprotection (Castellano et al. 2006). Moreover, in a subsequent study an increase in BCATc in response to BDNF was particular to the parietal cortex, 


\section{BCAT IN THE BRAIN}

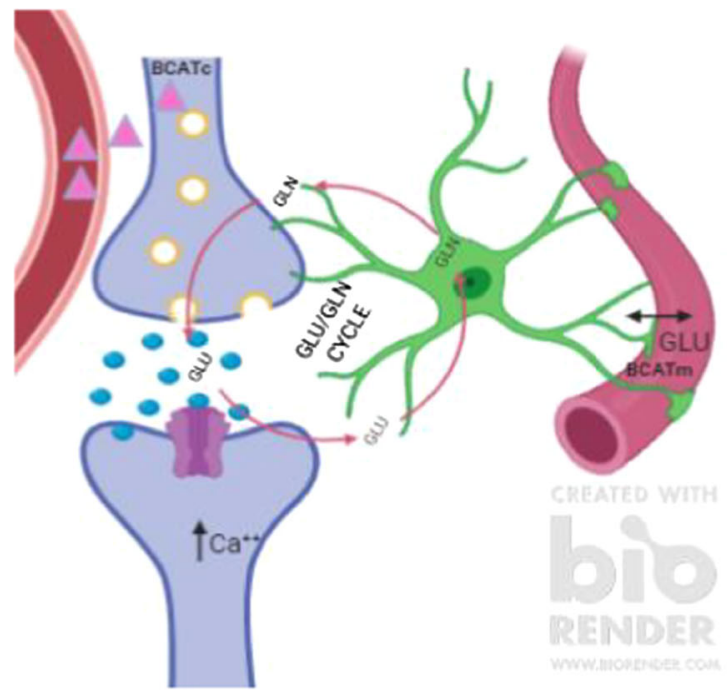

Fig. 6 BCAT metabolism in the human brain. Under conditions where excitotoxicity persists, astrocytes are ineffective at clearing excess glutamate. This results in the post synaptic overstimulation of NMDA receptors causing calcium overload

the hilus and CA3 hippocampal subfield (Madeddu et al. 2004). These regional increases support a role for BCATc in neuronal survival in areas heavily populated with glutamatergic neurons and indicate that BCAT metabolic activity is important under conditions that threaten cell survival. Therefore, it is possible that in AD too the upregulation of BCAT is a physiological response, as in general the neurons that were immunopositive for BCATc in the human brain tissue also appeared morphologically intact. Importantly, the immunohistochemistry data, showed that the intensity of BCATc labelling in both cell bodies and dendrites was most pronounced in the hippocampus, a region that is known to be particularly susceptible to excitotoxic neuronal injury at an early stage of $\mathrm{AD}$, highlighting that sustained increase in BCATc may contribute to injury. In addition, the antiepileptic drug gabapentin, which inhibits BCATc, has proved successful in treating behavioural alterations in subjects with AD (Cooney et al. 2013; Supasitthumrong et al. 2019). A more widespread increase in the level of BCATm was also reported that extended throughout the frontal and temporal regions of $\mathrm{AD}$ brain. An increase in BCATm was also reported in cases with dementia with Lewy bodies and vascular dementia (Ashby et al. 2017). Similar to BCATc, we

\section{BCAT IN ALZHEIMER'S BRAIN}

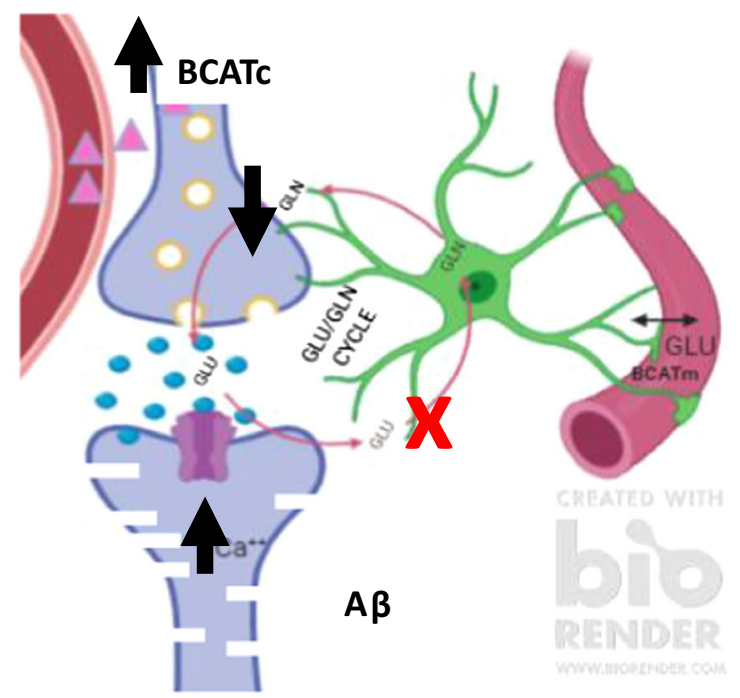

and ROS-related cell death. Moreover, levels of BCATc are increased in glutamatergic neurons, increasing the synthesis of glutamate, exacerbating neuronal toxicity. (Image generated using BioRender)

propose that increased levels of endothelial BCATm would serve in a neuroprotective capacity. As astrocyte uptake is poor the endothelial system may operate as an auxiliary mechanism to support glutamate efflux (Hull et al. 2015a, b). However, further studies are required to fully determine the impact of increased BCAT levels in AD brain.

More recently, we reported that serum BCAT was also higher in $\mathrm{AD}$ individuals relative to healthy agematched controls (Hudd et al. 2019). In this study we adopted a combined approach to generate a differential diagnosis of people presenting with MCI that will progress to AD. To this end, we used a battery of cognitive assessments together with magnetic resonance imaging and serum analysis of BCAT, the BCAAs and the aromatic amino acids. Our data shows a substantive mutually correlated system between BCAT and glutamate, neurophysiological tests and magnetic resonance imaging for the diagnosis of $\mathrm{AD}$. Our model showed that BCAT and glutamate accurately distinguish between control and $\mathrm{AD}$ participants and in combination with the neurophysiological test Montreal Cognitive Assessment, improved the overall sensitivity to 1.00 and specificity to 0.978 . This study indicated that BCAT and glutamate hold promise as early indicators of disease pathology. However, a 
limitation to this study was the timeframe, where a longitudinal study would better define the utility of BCAT and glutamate as biomarkers.

\section{Moonlighting roles for BCAT}

Although the canonical role for BCAT has traditionally been associated with transamination and glutamate regulation, it is important to note that it is also a redox-sensitive protein subject to oxidation (Conway et al. 2002), S-nitrosylation (Conway et al. 2004) and S-glutathionylation (Conway et al. 2008). Whilst the role of BCAT in regulating brain glutamate is established the importance of the redox switch has yet to be fully appreciated, in particular under conditions that affect the redox state of the cell. This redox switch is unique to these aminotransferases and has been shown to be important in regulating metabolite shuttling between the BCKD complex and GDH (Islam et al. 2007). This is inhibited through oxidation that not only inactivates BCAT but also destabilises the metabolic complexes (Islam et al. 2010). Targeted proteomic studies have indicated that the BCAT proteins have additional binding partners governed by their CXXC motif (Coles et al. 2009; Hindy and Conway 2019). These include proteins important in cell signalling and protein folding (e.g. BCAT was identified as a novel chaperone in protein folding through its thiol oxidoreductase activity, El Hindy et al. 2014). Our most recent study offers evidence that these 'moonlighting' functions are fundamental in regulating autophagy and play a fundamental role in regulating $A \beta$ (Harris et al. 2020). Here, BCATc-mediated autophagy was shown to be regulated through PKC-mediated phosphorylation, modulated by the redox state of BCATc. Using the SH-SY5Y cell model, we showed that overexpression of BCATc, as observed in AD brain, resulted in $A \beta$ accumulation through an increase in autophagosome synthesis. Importantly, leucine, a key regulator of autophagic flux, significantly reduced BCATcinduced autophagy and consequently $A \beta$. Our data supports a novel mechanism by which $A \beta$ accumulation may be altered by BCAAs such as leucine, but subject to a more in-depth understanding of nutritional signalling in aging and neurodegenerative conditions such as AD.

\section{Disorders of BCAA metabolism}

Maple syrup urine disease (MSUD)

Excess or limiting dietary BCAAs cause neurological dysfunction, reducing cognitive function. The autosomal recessive congenital disease, MSUD, is clinically characterised by an accumulation of both BCAAs and their respective $\alpha$-keto-acid derivatives that are severely toxic to cells (Dancis et al. 1960; Menkes 1959). In untreated cases, infants present with symptoms including neurological dysfunction, seizures and infant death (Chuang et al. 2006). Five classifications of MSUD have been identified (varying from severe classic forms to mild variant types with an additional thiamine responsive form) based on the residual BCKD activity, the age of onset and the concentration of leucine in serum (Chuang and Chuang 2000). Although treatment through restriction of the BCAAs in the diet has most value in milder forms of the condition, patients that are not compliant with their diet or those with more severe forms of the disease are still subject to many side effects.

Mutations of BCAT leads to mild cognitive impairment and brain lesions

Until recently, mutations of the BCAT gene that manifest clinically were not reported. However, Wang et al. (2015a, b) first reported a case of a 22 year-old male who presented with MCI, lasting longer than 6 years, headaches and a striking blood profile of hypervalinaemia, hyperleucinemia and isoleucinemia, which aligned with a diagnosis of MSUD (Wang et al. 2015a, b). Mutations linked with MSUD were not indicated nor did the patient present with the classical smell of maple syrup from his urine. Although MRI imaging showed associated brain white matter lesions, a feature of MSUD (Jan et al. 2003; Schonberger et al. 2004), brain regions affected in MSUD patients are mainly in the mesencephalon and brain stem as well as thalamus and globus pallidus (Schonberger et al. 2004), whereas in this patient, supratentorial lesions were found without overt abnormalities in these regions. Neuronal damage due to prolonged high brain BCAA concentrations was reported using MRS imaging. Sequencing analysis revealed two heterogeneous mutations including: c.509G $>$ A (p.Arg170Gln) and c.790G $>$ A (p.Glu264Lys). 
Interestingly, c.509G $>$ A (p.Arg170Gln) was found in his father while c.790G >A (p.Glu264Lys) was found in his mother. Whilst leucine concentrations are usually the highest among the BCAA that are increased in MSUD, valine was shown to be the highest in this case. Moreover, treatment of the patient with vitamin B6 resulted in a sharp decline in valine levels compared with those of leucine and isoleucine. A more recent study identified several additional BCAT2 mutations that ranged between homozygous or compound heterozygous BCAT2 mutations (Knerr et al. 2019). The authors reported similar biochemical profiles i.e. raised plasma BCAA with wide-ranging cognitive challenges. Other distinguishable features from MSUD such as low-normal BCKAs with undetectable L-allo-isoleucine and absence of acute encephalopathy even with exceptionally high BCAA levels were evident. The mechanisms underlying the brain damage observed in these patients are not well established but will most likely be related to the increased BCAA levels similar to that reported for MSUD (Yudkoff 1997; Barschak et al. 2009; Funchal et al. 2006; Sgaravatti et al. 2003). Decreased transamination would also impact Glu regeneration potentially explaining the MCI presentation.

Serum BCAA indicators of brain injury

Traumatic brain injury (TBI) is defined as an insult to the brain from an external mechanical force, which can lead to temporary or permanent cognitive impairment dependent on the injury. Following TBI, there is combined metabolic response including Glu toxicity, secondary brain oedema and increased cranial pressure (Vuille-Dit-bille et al. 2012). Interestingly, studies have reported a significant decrease in the plasma BCAAs, whereas the aromatic amino acids (phenylalanine, tryptophan and tyrosine) were increased (Vuille-Dit-bille et al. 2012; Jeter et al. 2013). The BCAAs and aromatic amino acids utilise the same transporters to access the brain. Should the levels of the BCAA decrease then uptake of the aromatic amino acids would exceed that of BCAAs, increasing the synthesis of serotonin and dopamine (Fernstrom and Fernstrom 2007; Scarna et al. 2005). As the BCAA are important nutrient signals in regulating brain Glu, a decrease would signal a reduction in brain repair and dysregulation of glutamate metabolism. In patients with TBI, it was demonstrated that supplementation with BCAA improved cognition and has in some cases improved recovery from a vegetative or minimally conscious state (Aquilani et al. 2008a, 2008). Using an animal model of TBI, Cole et al. (2010) reported improved cognition in rats supplemented with BCAAs following lateral fluid percussion injury. Collectively, these results support a role for BCAA in regulating brain Glu and can impact associated cognitive function. Therefore, additional studies are required to determine the concentration of dietary BCAA that could be beneficial to neurological and neurodegenerative conditions where glutamate toxicity factors.

\section{Conclusion}

Clearly, regulation of brain glutamate is important in AD pathology. Substantial evidence supports a role for ineffective astrocytic clearance of glutamate released during excitation. Moreover, oligomeric $\mathrm{A} \beta$ has been shown to interact with glutamate receptors contributing to glutamate excitotoxicity (Hascup and Hascup 2016). Clinically, a role for excitotoxicity in AD pathology is underpinned by the approval of memantine to treat moderate to severe confusion related to AD. Although it does not cure AD it can improve memory, awareness and the ability to carry out day-today activities. However, this medication only targets the NMDA receptor, which although reduces excitotoxicity, it does not address other aspects of brain glutamate regulation. As discussed the BCAA and aromatic amino acids are important sources of neurotransmitter synthesis. In disease conditions it is clear that excess (MSUD and BCAT2) or limiting (TBI) amounts of these amino acids result in altered cognitive function. Moreover, mutations in key metabolic enzymes specific to BCAA metabolism, such as BCAT2 and the BCKD complex, result in blood profiles that show BCAAs or BCAA and $\alpha$-keto acids accumulation, respectively. Treatment through Vitamin B supplementation (BCAT2), BCAA restriction (MSUD), or supplementation (TBI) has improved cognitive outcome. Given that BCAT is increased in key areas of the brain associated with $\mathrm{AD}$ pathology and that serum BCAT levels reflect cognitive outcomes it lends weight to further investigate the wider role that BCAT metabolism has on not just glutamate regulation but other pathways associated with $\mathrm{AD}$ pathology. 
Open Access This article is licensed under a Creative Commons Attribution 4.0 International License, which permits use, sharing, adaptation, distribution and reproduction in any medium or format, as long as you give appropriate credit to the original author(s) and the source, provide a link to the Creative Commons licence, and indicate if changes were made. The images or other third party material in this article are included in the article's Creative Commons licence, unless indicated otherwise in a credit line to the material. If material is not included in the article's Creative Commons licence and your intended use is not permitted by statutory regulation or exceeds the permitted use, you will need to obtain permission directly from the copyright holder. To view a copy of this licence, visit http://creativecommons.org/licenses/by/4.0/.

\section{References}

Albin RL, Greenamyre JT (1992) Alternative excitotoxic hypotheses. Neurology 42(4):733-738

Antuono PG, Jones JL, Wang Y, Li SJ (2001) Decreased glutamate+glutamine in Alzheimer's disease detected in vivo with (1)H-MRS at $0.5 \mathrm{~T}$. Neurology 56(6):737-742

Aquilani R, Boselli M, Boschi F, Viglio S, Iadarola P, Dossena M, Pastoris O, Verri M (2008a) Branched-chain amino acids may improve recovery from a vegetative or minimally conscious state in patients with traumatic brain injury: a pilot study. Arch Phys Med Rehabil 89(9): 1642-1647

Aquilani R, Scocchi M, Iadarola P, Franciscone P, Verri M, Boschi F, Pasini E, Viglio S (2008b) Protein supplementation may enhance the spontaneous recovery of neurological alterations in patients with ischaemic stroke. Clin Rehabil 22(12):1042-1050

Ashby EL, Kierzkowska M, Hull J, Kehoe PG, Hutson SM, Conway ME (2017) Altered expression of human mitochondrial branched chain aminotransferase in dementia with lewy bodies and vascular dementia. Neurochem Res 42(1):306-319

Association A (2016) 2016 Alzheimer's disease facts and figures. Alzheimers Dement 12(4):459-509

Barschak AG, Sitta A, Deon M, Busanello EN, Coelho DM, Cipriani F, Dutra-Filho CS, Giugliani R, Wajner M, Vargas CR (2009) Amino acids levels and lipid peroxidation in maple syrup urine disease patients. Clin Biochem 42(6):462-466

Benussi A, Alberici A, Buratti E, Ghidoni R, Gardoni F, Di Luca M, Padovani A, Borroni B (2019) Toward a glutamate hypothesis of frontotemporal dementia. Front Neurosci 13:304

Bixel MG, Hutson SM, Hamprecht B (1997) Cellular distribution of branched-chain amino acid aminotransferase isoenzymes among rat brain glial cells in culture. J Histochem Cytochem 45(5):685-694

Bixel M, Shimomura Y, Hutson S, Hamprecht B (2001) Distribution of key enzymes of branched-chain amino acid metabolism in glial and neuronal cells in culture. J Histochem Cytochem 49(3):407-418

Bookheimer SY, Strojwas MH, Cohen MS, Saunders AM, Pericak-Vance MA, Mazziotta JC, Small GW (2000)
Patterns of brain activation in people at risk for Alzheimer's disease. N Engl J Med 343(7):450-456

Bouvier M, Szatkowski M, Amato A, Attwell D (1992) The glial cell glutamate uptake carrier counter transports $\mathrm{pH}$ changing anions. Nature 360(6403):471-474

Brand K (1981) Metabolism of 2-oxoacid analogues of leucine, valine and phenylalanine by heart muscle, brain and kidney of the rat. Biochim Biophys Acta 677(1):126-132

Brand K, Hauschildt S (1984) Metabolism of 2-oxo-acid analogues of leucine and valine in isolated rat hepatocytes. Hoppe Seylers Z Physiol Chem 365(4):463-468

Bussiere T, Giannakopoulos P, Bouras C, Perl DP, Morrison JH, Hof PR (2003) Progressive degeneration of nonphosphorylated neurofilament protein-enriched pyramidal neurons predicts cognitive impairment in Alzheimer's disease: stereologic analysis of prefrontal cortex area 9. J Comp Neurol 463:281-382

Cai Z, Hussain MD, Yan LJ (2014) Microglia, neuroinflammation, and beta-amyloid protein in Alzheimer's disease. Int J Neurosci 124(5):307-321

Castellano S, Macchi F, Scali M, Huang JZ, Bozzi Y (2006) Cytosolic branched chain aminotransferase (BCATc) mRNA is up-regulated in restricted brain areas of BDNF transgenic mice. Brain Res 1108(1):12-18

Castellano S, Casarosa S, Sweatt AJ, Hutson SM, Bozzi Y (2007) Expression of cytosolic branched chain aminotransferase (BCATc) mRNA in the developing mouse brain. Gene Expr Patterns 7(4):485-490

Chan PH, Fishman RA (1978) Brain edema: induction in cortical slices by polyunsaturated fatty acids. Science 201:358-360

Chaplin ER, Goldberg AL, Diamond I (1976) Leucine oxidation in brain slices and nerve endings. $J$ Neurochem 26(4):701-707

Chaudhry FA, Lehre KP, van Lookeren Campagne M, Ottersen OP, Danbolt NC, Storm-Mathisen J (1995) Glutamate transporters in glial plasma membranes: highly differentiated localizations revealed by quantitative ultrastructural immunocytochemistry. Neuron 15(3):711-720

Choi DW, Maulucci-Gedde M (1987) Kriegstein AR Glutamate neurotoxicity in cortical cell culture. J Neurosci 7(2):357-368

Chuang JL, Chuang DT (2000) Diagnosis and mutational analysis of maple syrup urine disease using cell cultures. Methods Enzymol 324:413-423

Chuang DT, Chuang JL, Wynn RM (2006) Lessons from genetic disorders of branched-chain amino acid metabolism. J Nutr 136(1 Suppl):243S-S249

Clements JD, Lester RA, Tong G, Jahr CE, Westbrook GL (1992) The time course of glutamate in the synaptic cleft. Science 258:1498-1501

Cole JT, Mitala CM, Kundu S, Verma A, Elkind JA, Nissim I, Cohen AS (2010) Dietary branched chain amino acids ameliorate injury-induced cognitive impairment. Proc Natl Acad Sci USA 107(1):366-371

Collingridge GL, Lester RAJ (1989) Excitatory amino acid receptors in the vertebrate central nervous system. Pharmacol Rev 40:143-210

Conway ME, Hutson SM (2016) BCAA metabolism and NH(3) homeostasis. Adv Neurobiol 13:99-132 
Conway ME, Yennawar N, Wallin R, Poole LB, Hutson SM (2002) Identification of a peroxide-sensitive redox switch at the CXXC motif in the human mitochondrial branched chain aminotransferase. Biochemistry 41(29):9070-9078

Conway ME, Poole LB, Hutson SM (2004) Roles for cysteine residues in the regulatory $\mathrm{CXXC}$ motif of human mitochondrial branched chain aminotransferase enzyme. Biochemistry 43(23):7356-7364

Conway ME, Coles SJ, Islam MM, Hutson SM (2008) Regulatory control of human cytosolic branched-chain aminotransferase by oxidation and S-glutathionylation and its interactions with redox sensitive neuronal proteins. Biochemistry 47(19):5465-5479

Cooney C, Murphy S, Tessema H, Freyne A (2013) Use of lowdose gabapentin for aggressive behavior in vascular and Mixed Vascular/Alzheimer Dementia. J Neuropsychiatry Clin Neurosci 25(2):120-125

Daikhin Y, Yudkoff M (1026S) Compartmentation of brain glutamate metabolism in neurons and glia. J Nutr 130(4S Suppl):1026S-S1031

Danbolt NC (2001) Glutamate uptake. Prog Neurobiol 65(1):1-105

Dancis J, Levitz M, Westall RG (1960) Maple syrup urine disease: branched-chain keto-aciduria. Pediatrics 25:72-79

Duan AR, Jonasson EM, Alberico EO, Li C, Scripture JP, Miller RA, Alber MS, Goodson HV (2017) Interactions between Tau and different conformations of tubulin: implications for tau function and mechanism. $\mathrm{J}$ Mol Biol 429(9): 1424-1438

Dubinsky JM (1993) Intracellular calcium levels during the period of delayed excitotoxicity. J Neurosci 13:623-631

El Hindy M, Hezwani M, Corry D, Hull J, El Amraoui F, Harris M, Lee C, Forshaw T, Wilson A, Mansbridge A, Hassler M, Patel VB, Kehoe PG, Love S, Conway ME (2014) The branched-chain aminotransferase proteins: novel redox chaperones for protein disulfide isomerase-implications in Alzheimer's disease. Antioxid Redox Signal 20(16):2497-2513

Fayed N, Modrego PJ, Rojas-Salinas G, Aguilar K (2011) Brain glutamate levels are decreased in Alzheimer's disease: a magnetic resonance spectroscopy study. Am J Alzheimer's Dis Other Dement 26:450-456

Featherstone DE, Shippy SA (2008) Regulation of synaptic transmission by ambient extracellular glutamate. Neuroscientist 14(2):171-181

Fernstrom J (2005) Branched-chain amino acids and brain function. J Nutr 135:1539S-1546S

Fernstrom JD, Fernstrom MH (1548S) Tyrosine, phenylalanine, and catecholamine synthesis and function in the brain. J Nutr 137(6 Suppl 1):1539S-1547S (discussion1548S)

Ferreira-Vieira TH, Guimaraes IM, Silva FR, Ribeiro FM (2016) Alzheimer's disease: targeting the cholinergic system. Curr Neuropharmacol 14(1):101-115

Funchal C, Latini A, Jacques-Silva MC, Dos Santos AQ, Buzin L, Gottfried C, Wajner M, Pessoa-Pureur R (2006) Morphological alterations and induction of oxidative stress in glial cells caused by the branched-chain alpha-keto acids accumulating in maple syrup urine disease. Neurochem Int 49(7):640-650

Gamberino WC, Berkich DA, Lynch CJ, Xu B, LaNoue KF (1997) Role of pyruvate carboxylase in facilitation of synthesis of glutamate and glutamine in cultured astrocytes. J Neurochem 69(6):2312-2325

Gao F, Edden RAE, Li M, Puts NAJ, Wang G, Liu C, Zhao B, Wang H, Bai X, Zhao C, Wang X, Barker PB (2013) Edited magnetic resonance spectroscopy detects an age-related decline in brain GABA levels. Neuroimage 78:75-82

García-Espinosa MA, Wallin R, Hutson SM, Sweatt AJ (2007) Widespread neuronal expression of branched-chain aminotransferase in the CNS: implications for leucine/ glutamate metabolism and for signaling by amino acids. J Neurochem 100(6):1458-1468

Gottlieb M, Wang Y, Teichberg VI (2003) Blood-mediated scavenging of cerebrospinal fluid glutamate. J Neurochem 87(1):119-126

Hall TR, Wallin R, Reinhart GD et al (1993) Branched chain aminotransferase isoenzymes. Purification and characterization of the rat brain isoenzyme. $\mathrm{J}$ Biol Chem. 268(5):3092-3098

Hall H, Cuellar-Baena S, Dahlberg C, In't Zandt R, Denisov V, Kirik D (2012) Magnetic resonance spectroscopic methods for the assessment of metabolic functions in the diseased brain. Curr Top Behav Neurosci 11:169-198

Harris RA, Joshi M, Jeoung NH (2004) Mechanisms responsible for regulation of branched-chain amino acid catabolism. Biochem Biophys Res Commun 313(2):391-396

Harris M, El Hindy M, Usmari-Moraes M, Hudd F, Shafei M, Dong M, Hezwani M, Clark P, House M, Forshaw T, Kehoe P, Conway ME (2020) BCAT-induced autophagy regulates $A \beta$ load through an interdependence of redox state and PKC phosphorylation-implications in Alzheimer's disease. Free Radic Biol Med. https://doi.org/10. 1016/j.freeradbiomed.2020.01.019

Hascup KN, Hascup ER (2016) Soluble amyloid- $\beta 42$ stimulates glutamate release through activation of the $\alpha 7$ nicotinic acetylcholine receptor. J Alzheimers Dis 53(1):337-47

Helms HC, Madelung R, Waagepetersen HS, Nielsen CU, Brodin B (2012) In vitro evidence for the brain glutamate efflux hypothesis: Brain endothelial cells cocultured with astrocytes display a polarized brain-to-blood transport of glutamate. Glia 60:882-893

Hindy MEL, Conway ME (2019) Redox-regulated, targeted affinity isolation of NADH-dependent protein interactions with the branched chain aminotransferase proteins. Methods Mol Biol 1990:151-163. https://doi.org/10.1007/9781-4939-9463-2_13

Hosoya K, Sugawara M, Asaba H, Terasaki T (1999) Bloodbrain barrier produces significant efflux of L-aspartic acid but not D-aspartic acid: in vivo evidence using the brain efflux index method. J Neurochem 73(3):1206-1211

Huang S, Tong H, Lei M, Zhou M, Guo W, Li G, Tang X, Li Z, Mo M, Zhang X, Chen X, Cen L, Wei L, Xiao Y, Li K, Huang Q, Yang X, Liu W, Zhang L, Qu S, Li S, Xu P (2018) Astrocytic glutamatergic transporters are involved in $\mathrm{A} \beta$-induced synaptic dysfunction. Brain Res 1678:129-137

Hudd F, Shiel A, Harris M, Bowdler P, McCann B, Tsivos D, Wearn A, Knight M, Kauppinen R, Coulthard E, White P, Conway ME (2019) Novel blood biomarkers that correlate with cognitive performance and hippocampal volumetry: potential for early diagnosis of alzheimer's disease. J Alzheimers Dis 67(3):931-947 
Hull J, Hindy ME, Kehoe PG, Chalmers K, Love S, Conway ME (2012) Distribution of the branched chain aminotransferase proteins in the human brain and their role in glutamate regulation. J Neurochem. 123(6):997-1009

Hull J, Patel V, El-Hindy M, Lee C, Odeleye E, Hezwani M, Love S, Kehoe P, Chalmers K, Conway M (2015a) Regional increase in the expression of the bcat proteins in Alzheimer's disease brain: implications in glutamate toxicity. J Alzheimers Dis 45(3):891-905

Hull J, Patel VB, Hutson SM, Conway ME (2015b) New insights into the role of the branched-chain aminotransferase proteins in the human brain. J Neurosci Res 93(7):987-998

Hull J, Usmari Moraes M, Brookes E, Love S, Conway ME (2018) Distribution of the branched-chain $\alpha$-ketoacid dehydrogenase complex E1 $\alpha$ subunit and glutamate dehydrogenase in the human brain and their role in neurometabolism. Neurochem Int 112:49-58

Hutson SM (1988) Subcellular distribution of branched-chain aminotransferase activity in rat tissues. $J$ Nutr 118(12):1475-1481

Hutson SM, Harper AE (1981) Blood and tissue branched-chain amino and alpha-keto acid concentrations: effect of diet, starvation, and disease. Am J Clin Nutr 34(2):173-183

Hutson SM, Cree TC, Harper AE (1978) Regulation of leucine and alpha-ketoisocaproate metabolism in skeletal muscle. J Biol Chem 253(22):8126-8133

Hutson SM, Berkich D, Drown P, Xu B, Aschner M, LaNoue KF (1998) Role of branched-chain aminotransferase isoenzymes and gabapentin in neurotransmitter metabolism. J Neurochem 71(2):863-874

Hutson SM, Lieth E, LaNoue KF (2001) Function of leucine in excitatory neurotransmitter metabolism in the central nervous system. J Nutr 131(3):846S-850S

Hutson SM, Islam MM, Zaganas I (2011) Interaction between glutamate dehydrogenase (GDH) and L-leucine catabolic enzymes: intersecting metabolic pathways. Neurochem Int 59(4):518-524

Hynd MR, Scott HL, Dodd PR (2004) Glutamate-mediated excitotoxicity and neurodegeneration in Alzheimer's disease. Neurochem Int 45(5):583-595

Ichihara A, Koyama E (1966) Transaminase of branched chain amino acids. J Biochem 59:160-169

Islam MM, Wallin R, Wynn RM, Conway M, Fujii H, Mobley JA, Chuang DT, Hutson SM (2007) A novel branchedchain amino acid metabolon. Protein-protein interactions in a supramolecular complex. J Biol Chem 282(16):11893-11903

Islam MM, Nautiyal M, Wynn RM et al (2010) Branched-chain amino acid metabolon: interaction of glutamate dehydrogenase with the mitochondrial branched-chain aminotransferase (BCATm). J Biol Chem 285(1):265-276

Jacob CP, Koutsilieri E, Bartl J, Neuen-Jacob E, Arzberger T, Zander N, Ravid R, Roggendorf W, Riederer P, Grünblatt E (2007) Alterations in expression of glutamatergic transporters and receptors in sporadic Alzheimer's disease. J Alzheimers Dis 11(1):97-116

Jan W, Zimmerman RA, Wang ZJ, Berry GT, Kaplan PB, Kaye EM (2003) MR diffusion imaging and MR spectroscopy of maple syrup urine disease during acute metabolic decompensation. Neuroradiology 45(6):393-399
Jeter CB, Hergenroeder GW, Ward III NH, Moore AN, Dash PK (2013) Human mild traumatic brain injury decreases circulating branched-chain amino acids and their metabolite levels. J Neurotrauma 30(8):671-679

Kaiser LG, Schuff N, Cashdollar N, Weiner MW (2005) Agerelated glutamate and glutamine concentration changes in normal human brain: $1 \mathrm{H}$ MR spectroscopy study at $4 \mathrm{~T}$. Neurobiol Aging 26(5):665-672

Kalra S (2019) Magnetic resonance spectroscopy in ALS. Front Neurol 10:482

Kanamori K, Ross BD, Kondrat RW (1998) Rate of glutamate synthesis from leucine in rat brain measured in vivo by ${ }^{15} \mathrm{~N}$ NMR. J Neurochem 70(3):1304-1315

Kantarci K (2007) Magnetic resonance spectroscopy in dementia. Br J Radiol. 80(Spec No 2):S146-S152

Kantarci K, Murray ME, Schwarz CG, Reid RI, Przybelski SA, Lesnick T, Zuk SM, Raman MR, Senjem ML, Gunter JL, Boeve BF, Knopman DS, Parisi JE, Petersen RC, Jack CR Jr, Dickson DW (2017) White-matter integrity on DTI and the pathologic staging of Alzheimer's disease. Neurobiol Aging 56:172-179. https://doi.org/10.1016/j. neurobiolaging.2017.04.024

Kholodilov N, Neystat M, Oo T, Hutson S, Burke R (2000) Upregulation of cytosolic branched chain aminotransferase in substantia nigra following developmental striatal target injury. Mol Brain Res 75:281-286

Kilian JG, Hsu HW, Mata K, Wolf FW, Kitazawa M (2017) Astrocyte transport of glutamate and neuronal activity reciprocally modulate tau pathology in Drosophila. Neuroscience 348:191-200

Kishi T, Matsunaga S, Oya K, Nomura I, Ikuta T, Iwata N (2017) Memantine for Alzheimer's Disease: an updated systematic review and meta-analysis. $J$ Alzheimers Dis 60(2):401-425

Knerr I, Colombo R, Urquhart J, Morais A, Merinero B, Oyarzabal A, Pérez B, Jones SA, Perveen R, Preece MA, Rogers Y, Treacy EP, Mayne P, Zampino G, MacKinnon S, Wassmer E, Yue WW, Robinson I, Rodríguez-Pombo P, Olpin SE, Banka S (2019) Expanding the genetic and phenotypic spectrum of branched-chain amino acid transferase 2 deficiency. J Inherit Metab Dis 42(5):809-817

Koh JY, Choi DW (1991) Selective blockade of non-NMDA receptors does not block rapidly triggered glutamate-induced neuronal death. Brain Res 548(1-2):318-321

Lane CA, Hardy J, Schott JM (2018) Alzheimer's disease. Eur J Neurol 25(1):59-70

LaNoue KF, Berkich DA, Conway M, Barber AJ, Hu LY, Taylor C, Hutson S (2001) Role of specific aminotransferases in de novo glutamate synthesis and redox shuttling in the retina. J Neurosci Res 66(5):914-922

Lazarewicz JW, Wroblewski JT, Costa E (1990) N-Methyldaspartate-sensitive glutamate receptors induce calciummediated arachidonic acid release in primary cultures of cerebellar granule cells. J Neurochem 55:1875-1881

Lieth E, LaNoue KF, Berkich DA, Xu B, Ratz M, Taylor C, Hutson SM (2001) Nitrogen shuttling between neurons and glial cells during glutamate synthesis. J Neurochem 76(6):1712-1723

Lin HM, Kaneshige M, Zhao L, Zhang X, Hanover JA, Cheng SY (2001) An isoform of branched-chain aminotransferase 
is a novel co-repressor for thyroid hormone nuclear receptors. J Biol Chem 276(51):48196-48205

Liu J, Chang L, Song Y, Li H, Wu Y (2019) The role of NMDA receptors in Alzheimer's disease. Front Neurosci 13:43

Londono AC, Castellanos FX, Arbelaez A, Ruiz A, AguirreAcevedo DC, Richardson AM, Easteal S, Lidbury BA, Arcos-Burgos M, Lopera F (2014) An 1H-MRS framework predicts the onset of Alzheimer's disease symptoms in PSEN1 mutation carriers. Alzheimers Dement 10(5):552-561

Madeddu F, Naska S, Bozzi Y (2004) BDNF down-regulates the caspase 3 pathway in injured geniculo-cortical neurones. NeuroReport 15(13):2045-2049

Matsunaga S, Kishi T, Iwata N (2015) Memantine monotherapy for Alzheimer's disease: a systematic review and metaanalysis. PLoS ONE 10(4):e0123289

Mattson MP (1992) Effects of microtubule stabilization and destabilization on tau immunoreactivity in cultured hippocampal neurons. Brain Res 582(1):107-118

Mattson MP, Chan SL (2003) Neuronal and glial calcium signaling in Alzheimer's disease. Cell Calcium 34(4-5):385-397

Menkes JH (1959) Maple syrup disease; isolation and identification of organic acids in the urine. Pediatrics 23(2):348-353

Modrego PJ, Fayed N, Pina MA (2005) Conversion from mild cognitive impairment to probable Alzheimer's disease predicted by brain magnetic resonance spectroscopy. Am J Psychiatry 162:667-675

Moraes MU, Gaudet T (2018) Immunotherapeutic and pharmacological approaches for the treatment of Alzheimer's disease. Biosci Horiz. https://doi.org/10.1093/biohorizons/ hzy001/4969341

Nizzari M, Thellung S, Corsaro A, Villa V, Pagano A, Porcile C, Russo C, Florio T (2012) Neurodegeneration in Alzheimer disease: role of amyloid precursor protein and presenilin 1 intracellular signaling. J Toxicol 2012:187297

O'Brien RJ, Wong PC (2011) Amyloid precursor protein processing and Alzheimer's disease. Annu Rev Neurosci 34:185-204

O'Kane RL, Martínez-López I, DeJoseph MR, Viña JR, Hawkins RA (1999) $\mathrm{Na}(+)$-dependentglutamate transporters (EAAT1, EAAT2, and EAAT3) of the blood-brain barrier. A mechanism for glutamate removal. J Biol Chem 274(45):31891-31895

O'Kane RL, Viña JR, Simpson I, Hawkins RA (2004) Na+ dependent neutral amino acid transporters A, ASC, and N of the blood-brain barrier: mechanisms for neutral amino acid removal. American $\mathrm{J}$ Phys Endocrin Met 287(4):E622-E629

Oldendorf WH, Cornford ME, Brown WJ (1977) The large apparent work capability of the blood-brain barrier: a study of the mitochondrial content of capillary endothelial cells in brain and other tissues of the rat. Ann Neurol 1(5):409-417

Oz G, Berkich DA, Henry PG, Xu Y, LaNoue K, Hutson SM, Gruetter R (2004) Neuroglial metabolism in the awake rat brain: $\mathrm{CO}_{2}$ fixation increases with brain activity. J Neurosci 24(50):11273-11279

Reddy PH, Beal MF (2008) Amyloid beta, mitochondrial dysfunction and synaptic damage: implications for cognitive decline in aging and Alzheimer's disease. Trends Mol Med 14(2):45-53

Reitz C, Brayne C, Mayeux R (2011) Epidemiology of Alzheimer disease. Nat Rev Neurol 7:137-152

Riese F, Gietl A, Zölch N, Henning A, O’Gorman R, Kälin AM, Leh SE, Buck A, Warnock G, Edden RA, Luechinger R, Hock C, Kollias S, Michels L (2015) Posterior cingulate $\gamma$ aminobutyric acid and glutamate/glutamine are reduced in amnestic mild cognitive impairment and are unrelated to amyloid deposition and apolipoprotein E genotype. Neurobiol Aging 36(1):53-59

Rothman SM (1985) The neurotoxicity of excitatory amino acids is produced by passive chloride influx. J Neurosci 5:1483-1489

Rupsingh R, Borrie M, Smith M, Wells JL, Bartha R (2011) Reduced hippocampal glutamate in Alzheimer disease. Neurobiol Aging 32(5):802-810

Sattler R, Tymianski M (2000) Molecular mechanisms of calcium-dependent excitotoxicity. J Mol Med 78(1):3-13

Scarnà A, McTavish SF, Cowen PJ, Goodwin GM, Rogers RD (2005) The effects of a branched chain amino acid mixture supplemented with tryptophan on biochemical indices of neurotransmitter function and decision-making. Psychopharmacology 179(4):761-768

Schönberger S, Schweiger B, Schwahn B, Schwarz M, Wendel U (2004) Dysmyelination in the brain of adolescents and young adults with maple syrup urine disease. Mol Genet Metab 82(1):69-75

Sgaravatti AM, Rosa RB, Schuck PF, Ribeiro CA, Wannmacher CM, Wyse AT, Dutra-Filho CS, Wajner M (2003) Inhibition of brain energy metabolism by the alpha-keto acids accumulating in maple syrup urine disease. Biochim Biophys Acta 1639(3):232-238

Shank RP, Bennett GS, Freytag SO, Campbell GL (1985) Pyruvate carboxylase: an astrocyte-specific enzyme implicated in the replenishment of amino acid neurotransmitter pools. Brain Res 329(1-2):364-367

Siman R, Noszek JC (1988) Excitatory amino acids activate calpain I and induce structural protein breakdown in vivo. Neuron 1:279-287

Smith QR, Momma S, Aoyagi M, Rapoport SI (1987) Kinetics of neutral amino acid transport across the blood-brain barrier. J Neurochem 49(5):1651-1658

Sonnewald U, Westergaard N, Petersen SB, Unsgård G, Schousboe A (1993) Metabolism of [U-13C] glutamate in astrocytes studied by 13C NMR spectroscopy: incorporation of more label into lactate than into glutamine demonstrates the importance of the tricarboxylic acid cycle. J Neurochem 61(3):1179-1182

Su L, Blamire AM, Watson R, He J, Hayes L, O’Brien JT (2016) Whole-brain patterns of (1)H-magnetic resonance spectroscopy imaging in Alzheimer's disease and dementia with Lewy bodies. Transl Psychiatry 6(8):e877

Supasitthumrong T, Tunvirachaisakul C, Aniwattanapong D, Tangwongchai S, Chuchuen P, Tawankanjanachot I, Snabboon T, Hemrungrojn S, Carvalho AF, Maes M (2019) peripheral blood biomarkers coupled with the apolipoprotein e4 genotype are strongly associated with semantic and episodic memory impairments in elderly subjects with amnestic mild cognitive impairment and Alzheimer's disease. J Alzheimers Dis 71(3):797-811 
Suryawan A, Hawes JW, Harris RA et al (1998) A molecular model of human branched-chain amino acid metabolism. Am J Clin Nutr 68(1):72-81

Sweatt AJ, Garcia-Espinosa MA, Wallin R et al (2004a) Branched-chain amino acids and neurotransmitter metabolism: expression of cytosolic branched-chain aminotransferase (BCATc) in the cerebellum and hippocampus. J Comp Neuro 477(4):360-370

Sweatt AJ, Wood M, Suryawan A, Wallin R, Willingham MC, Hutson SM (2004b) Branched-chain amino acid catabolism: unique segregation of pathway enzymes in organ systems and peripheral nerves. Am J Physiol Endocrinol Metab 286(1):E64-76

Teichberg VI, Cohen-Kashi-Malina K, Cooper I, Zlotnik A (2009) Homeostasis of glutamate in brain fluids: an accelerated brain-to-blood efflux of excess glutamate is produced by blood glutamate scavenging and offers protection from neuropathologies. Neuroscience 158(1):301-308

Tellechea P, Pujol N, Esteve-Belloch P, Echeveste B, GarcíaEulate MR, Arbizu J, Riverol M (2018) Early- and lateonset Alzheimer disease: are they the same entity? Neurologia 33(4):244-253

Than NG, Sümegi B, Than GN, Bellyei S, Bohn H (2001) Molecular cloning and characterization of placental tissue protein 18 (PP18a)/human mitochondrial branched-chain aminotransferase (BCATm) and its novel alternatively spliced PP18b variant. Placenta 22(2-3):235-243

Tiwari S, Atluri V, Kaushik A, Yndart A, Nair M (2019) Alzheimer's disease: pathogenesis, diagnostics, and therapeutics. Int J Nanomedicine 14:5541-5554

Tolar M, Abushakra S, Sabbagh M (2019) The path forward in Alzheimer's disease therapeutics: reevaluating the amyloid cascade hypothesis. Alzheimers Dement. https://doi.org/ 10.1016/j.jalz.2019.09.075

Uchida Y, Ohtsuki S, Katsukura Y, Ikeda C, Suzuki T, Kamiie J, Terasaki T (2011) Quantitative targeted absolute proteomics of human blood-brain barrier transporters and receptors. J Neurochem 117(2):333-345

Vuille-Dit-Bille RN, Ha-Huy R, Stover JF (2012) Changes in plasma phenylalanine, isoleucine, leucine, and valine are associated with significant changes in intracranial pressure and jugular venous oxygen saturation in patients with severe traumatic brain injury. Amino Acids 43(3):1287-1296

Wang XL, Li CJ, Xing Y, Yang YH, Jia JP (2015a) Hypervalinemia and hyperleucine-isoleucinemia caused by mutations in the branched-chain-amino-acid aminotransferase gene. J Inherit Metab Dis 38(5):855-861

Wang H, Tan L, Wang HF, Liu Y, Yin RH, Wang WY, Chang XL, Jiang T, Yu JT (2015b) Magnetic resonance spectroscopy in Alzheimer's disease: systematic review and meta-analysis. J Alzheimers Dis 46(4):1049-1070

Wattmo C, Wallin ÅK (2017) Early-versus late-onset Alzheimer's disease in clinical practice: cognitive and global outcomes over 3 years. Alzheimers Res Ther 9(1):70

Yudkoff M (1997) Brain metabolism of branched-chain amino acids. Glia 21(1):92-98

Yudkoff M (2017) Interactions in the metabolism of glutamate and the branched-chain amino acids and ketoacids in the CNS. Neurochem Res. 42(1):10-18

Yudkoff M, Nissim I, Kim S, Pleasure D, Hummeler K, Segal S (1983) $[15 \mathrm{~N}]$ leucine as a source of $[15 \mathrm{~N}]$ glutamate in organotypic cerebellar explants. Biochem Biophys Res Commun 115(1):174-179

Yudkoff M, Daikhin Y, Nelson D, Nissim I, Erecińska M (1996) Neuronal metabolism of branched-chain amino acids: flux through the aminotransferase pathway in synaptosomes. J Neurochem 66(5):2136-2145

Zlotnik A, Gurevich B, Cherniavsky E, Tkachov S, MatuzaniRuban A, Leon A, Shapira Y, Teichberg VI (2008) The contribution of the blood glutamate scavenging activity of pyruvate to its neuroprotective properties in a rat model of closed head injury. Neurochem Res 33(6):1044-1050

Zlotnik A, Sinelnikov I, Gruenbaum BF, Gruenbaum SE, Dubilet M, Dubilet E, Leibowitz A, Ohayon S, Regev A, Boyko M, Shapira Y, Teichberg VI (2012) Effect of glutamate and blood glutamate scavengers oxaloacetate and pyruvate on neurological outcome and pathohistology of the hippocampus after traumatic brain injury in rats. Anesthesiology 116(1):73-83

Publisher's Note Springer Nature remains neutral with regard to jurisdictional claims in published maps and institutional affiliations. 